\title{
Effect of Coexistence of Potassium and Sulphur on Abnormal Swelling during Reduction of Hematite Pellets
}

\author{
Shoji HAYASHI and Yoshiaki IGUCHI
}

Department of Materials Science and Engineering, Nagoya Institute of Technology, Gokiso-cho, Showa-ku, Nagoya, Aichi-ken 466, Japan.

(Received on July 4, 1988; accepted in the final form on April 14, 1989)

\begin{abstract}
In order to elucidate the effect of coexistence of potassium and sulphur on abnormal swelling during reduction of iron oxides, hematite pellets containing potassium carbonate have been reduced with sulphur bearing hydrogen base gas under the condition of gas starvation in the temperatures of 800 to $1000^{\circ} \mathrm{C}$.

The addition of $0.1 \sim 2.0 \mathrm{~mol} \% \mathrm{~K}_{2} \mathrm{CO}_{3}$ shows that normal swelling amounts to below $40 \%$ with macro- and microscopic cracks and that abnormal swelling reaches $300 \%$ at $800^{\circ} \mathrm{C}$ with coarse iron whiskers. This abnormal swelling due to only potassium takes place considerably regardless of any reduction history.

The abnormal swelling due to gaseous sulphur is observed in range of $10^{-2} \sim 1$ as sulphur activity of gas $\left(a_{S}\right)$ relative to $\mathrm{Fe} / \mathrm{FeS}$ equilibrium. The maximum swelling is $500 \%$ with fine iron whiskers in $a_{S}$ of 0.1 at $900^{\circ} \mathrm{C}$. It is found that sulphur has stronger abilities for the swelling than potassium.

The largest swelling is $600 \%$ and it is observed under coexistence of potassium and sulphur without the formation of liquid phase at $800^{\circ} \mathrm{C}$.

Actions of both additives during metallization is discussed in the light of authors' previous researches dealing with the effect of sulphur on reduction of wustite.
\end{abstract}

KEY WORDS: iron oxide pellets; hydrogen reduction; abnormal swelling; fibrous iron; potassium; gaseous sulphur; reduction history.

\section{Introduction}

It is known that the volumetric expansion during reduction of iron oxides is mainly classified into the normal swelling due to transformation of hematite to magnetite and the abnormal swelling with iron whiskers.

The authors have reported a series of works concerning the swelling ${ }^{1-3)}$ and made clear that the latter swelling occurs only when the following two conditions are satisfied: the presence of gaseous sulphur in the activity range of $10^{-3} \sim 1$ relative to $\mathrm{Fe} / \mathrm{FeS}$ equilibrium and the intermediate reduction rate of wustite to iron in either case of hydrogen reduction ${ }^{3)}$ and carbon monoxide reduction. 1,21

This swelling due to gaseous sulphur accompanied with iron whiskers first had been observed by Nicolle et al. ${ }^{4}$ and by Haas et al. ${ }^{5)}$ However, these studies had not made enough clear the sulphur potentials and the formation mechanism. Nicolle et al. explained the formation in relation to the characteristics of wustite surface and the mechanism controlling the overall reduction of a local wustite grain. Haas et al. interpreted it on the basis of the carbonization behaviour of metallic iron.

On the other hand, earlier researchers claimed that the abnormal swelling was caused by the presence of additives such as lime ${ }^{6-11)}$ and alkali, ${ }^{12-15)}$ and that random distribution of these species in iron oxides enhanced the swelling. ${ }^{16)}$ So, these workers payed no attention entirely to roles of the traces of sulphur in natural or synthetic iron oxides for swelling behaviour. Accordingly, the experiment in coexistence of potassium or lime and sulphur would have to be conducted as a next research to understand the mechanism of whisker formation in more detail.

On the basis of above viewpoints, the authors ${ }^{1,3}$ recently had accomplished the reduction experiments under the coexistence of lime and gaseous sulphur of above mentioned potential. In the absence of sulphur, the addition of $\mathrm{CaO}$ into iron oxides induced no abnormal swelling but normal swelling regardless of any reduction histories of hematite to wustite step. In the coexistence of $\mathrm{CaO}$ and sulphur, extraordinary swelling was observed with fine iron whiskers. Moreover, the less uniform the distribution of $\mathrm{CaO}$ in iron oxides, the greater the abnormal swelling in presence of sulphur. Sulphur was found to be the most important agent for abnormal swelling.

Although only a research in coexistence of potassium and sulphur has already been done using wustite pellets $^{1)}$ by the authors, experiments of higher iron oxides as starting materials is necessary to be carried out in order to make clear the effect of reduction history prior to wustite stage on the swelling and to develop the mechanism of formation of iron whiskers. Therefore, present works are conducted by using hematite pellets. Potassium is selected as a typical alkali because it usually accumulates to higher contents than sodium in blast furnace. ${ }^{173}$ 


\section{Experimentals}

A powder of chemical reagent ferric oxide was employed as a starting material, which is the same as used in the previous work. ${ }^{1)}$ After pelletizing the powder mixed with distilled water, the pellets were indurated in air for $1 \mathrm{~h}$ at $1300^{\circ} \mathrm{C}$ to remove its manufacturing history, subsequently crushed and screened under 200 mesh. These powders were mixed with potassium carbonate powder in the proportion as shown in Table 1, and indurated under the conditions in the Table, where the porosity of pellets and potassium content analysed by atomic absorption spectroscopy are also represented.

Isothermal reduction of single pellets was carried out by using a previous apparatus ${ }^{3}$ consisted of gas purification and thermobalance systems. $\mathrm{H}_{2}-\mathrm{H}_{2} \mathrm{O}-$ $\mathrm{H}_{2} \mathrm{~S}$ mixtures possessing the oxygen and sulphur potentials in which metallic iron remained stable were employed as reducing gas. The value of $P_{\mathrm{Hz}_{2} \mathrm{O}} / P_{\mathrm{H}_{2}}$ in gas was adopted to be mainly 0.25 from the results in later Figs. 6 and 7. The activity of sulphur in gas, $a_{\mathrm{S}}$, was defined as $\left(P_{\mathrm{H}_{2} \mathrm{~S}} / P_{\mathrm{H}_{2}}\right) /\left(P_{\mathrm{I}_{2} \mathrm{~S}} / P_{\mathrm{H}_{2}}\right)_{e}$, where $\left(P_{\mathrm{H}_{2} \mathrm{~S}} /\right.$ $\left.P_{\mathrm{II}_{2}}\right)_{e}{ }^{18,19)}$ is the gas ratio in equilibrium with iron and iron sulphide. The gas flow rate was fixed to be 200 $\mathrm{cm}^{3} / \min$. A previous study ${ }^{3)}$ had indicated in the same condition that the reduction proceeded under gas starvation.

The degree of swelling after partial reduction, $V$ $(\%)$, was calculated from Eq. (1), where $r_{0}$ and $r$ are average radii of a pellet before and after the reduction, respectively. Because the value of $V$ was proportional to the fractional reduction of wustite to iron $F_{w}$ until the reduction reached to the intermediate period as shown later in Fig. 1, the value of $V_{100}(\%)$ calculated from $\mathrm{Eq}$. (2) could be taken for a criterion of swelling. The pellets were reduced up to around $F_{W}=0.5$, below which the shrinkage of pelltes by sintering of reduced iron was almost negligible. The composition of the wustite is one in the equilibrium with metallic iron. ${ }^{201}$

$$
\begin{aligned}
& V=\left\{\left(r / r_{0}\right)^{3}-1\right\} \times 100 \\
& V_{100}=V / F_{W} \\
& \ldots \ldots \ldots \ldots
\end{aligned}
$$

Table 1. Preparation of hematite pellets and reducing

\begin{tabular}{|c|c|c|c|c|}
\hline \multirow{2}{*}{\multicolumn{2}{|c|}{$\begin{array}{c}\text { Addition of } \\
\mathrm{K}_{2} \mathrm{CO}_{3}\end{array}$}} & \multicolumn{2}{|c|}{ After induration* } & \multirow{3}{*}{$\begin{array}{l}\text { Reducing } \\
\text { condition }\end{array}$} \\
\hline & & \multirow{2}{*}{$\begin{array}{c}\mathrm{K}_{2} \mathrm{CO}_{3} * * \\
(w \mathrm{t} \%)\end{array}$} & \multirow{2}{*}{ Porosity } & \\
\hline$(\mathrm{mol} \%)$ & $(w t \%)$ & & & \\
\hline 0 & 0 & 0.0095 & $0.35 \sim 0.40$ & \multirow{6}{*}{$\begin{array}{l}\mathrm{H}_{2}-\mathrm{H}_{2} \mathrm{O}-\mathrm{H}_{2} \mathrm{~S} \\
\text { mixtures } \\
\left(200 \mathrm{~cm}^{3} / \mathrm{min}\right) \\
700,800,900, \\
1000^{\circ} \mathrm{C}\end{array}$} \\
\hline 0.1 & 0.0866 & 0.0297 & $0.33 \sim 0.36$ & \\
\hline 0.2 & 0.173 & 0.0761 & $0.32 \sim 0.35$ & \\
\hline 0.5 & 0.433 & 0.275 & $0.33 \sim 0.36$ & \\
\hline 1.0 & 0.867 & 0.508 & $0.34 \sim 0.36$ & \\
\hline 2.0 & 1.736 & 1.513 & $0.34 \sim 0.37$ & \\
\hline
\end{tabular}
condition.

* In air at $1000^{\circ} \mathrm{C}$ for $1 \mathrm{~h}$

** Atomic absorption spectroscopy

\section{Experimental Results}

\subsection{Swelling during Reduction of Hematite to Iron}

3.1.1. Effect of $F_{W}$ on Swelling

Effect of $F_{W}$ on swelling is shown in Fig. 1. Experiments of $0.5 \mathrm{~mol} \% \mathrm{~K}_{2} \mathrm{CO}_{3}$ doped hematite at $900^{\circ} \mathrm{C}$ indicate that values of $V$ decrease in later stage independently of the presence of sulphur. This lowering of swelling is likely owing to sintering of metallic iron.

\subsubsection{Effect of Potassium on Swelling}

In the absence of sulphur, the relation between values of $V_{100}$ and potassium content after induration is shown in Fig. 2 for each reduction temperature. The values of $V_{100}$ rised with increasing potassium and became nearly constant over the content of 0.5 $\mathrm{wt}_{\mathrm{t}} \% \mathrm{~K}_{2} \mathrm{CO}_{3}$. The maximum swelling of about 300 $\%$ was observed in $1.0 \mathrm{~mol}_{\%} \mathrm{~K}_{2} \mathrm{CO}_{3}$ doped hematite at $800^{\circ} \mathrm{C}$. The value of $R_{W}$ (see Sec. 3.3) was insensitive for alkali content.

\subsubsection{Sulphur Potential Dependence of Swelling}

Sulphur potential dependence of swelling is shown in Figs. 3 to 5 for 800,900 , and $1000^{\circ} \mathrm{C}$, respectively. At all the temperatures, abnormal swelling was observed in the range of $10^{-2} \sim 1$ in $a_{\mathrm{s}}$. The addition of

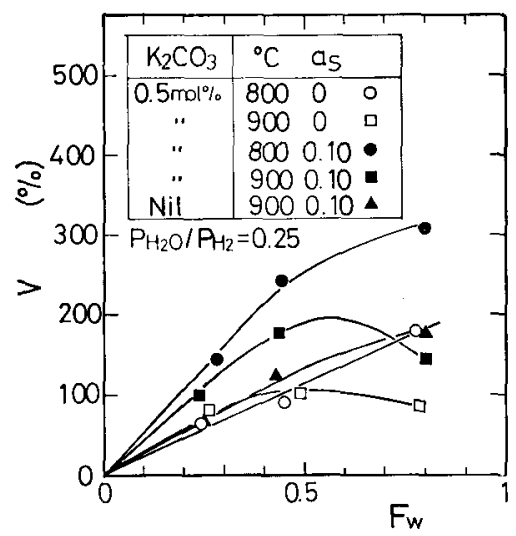

Fig. 1. Relation between swelling degree, $V$, and fractional reduction, $F_{W}$.

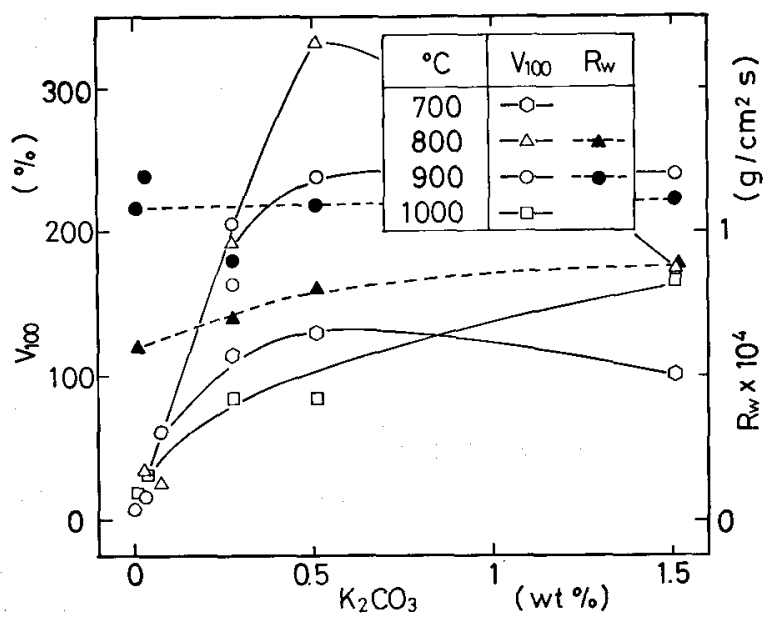

Fig. 2. Influences of $\mathrm{K}_{2} \mathrm{CO}_{3}$ content after induration and temperature on $V_{100}$ and $R_{W}\left(P_{\mathrm{H}_{2} \mathrm{O}} / P_{\mathrm{H}_{2}}=0.25, a_{\mathrm{S}}=\right.$ $0)$. 


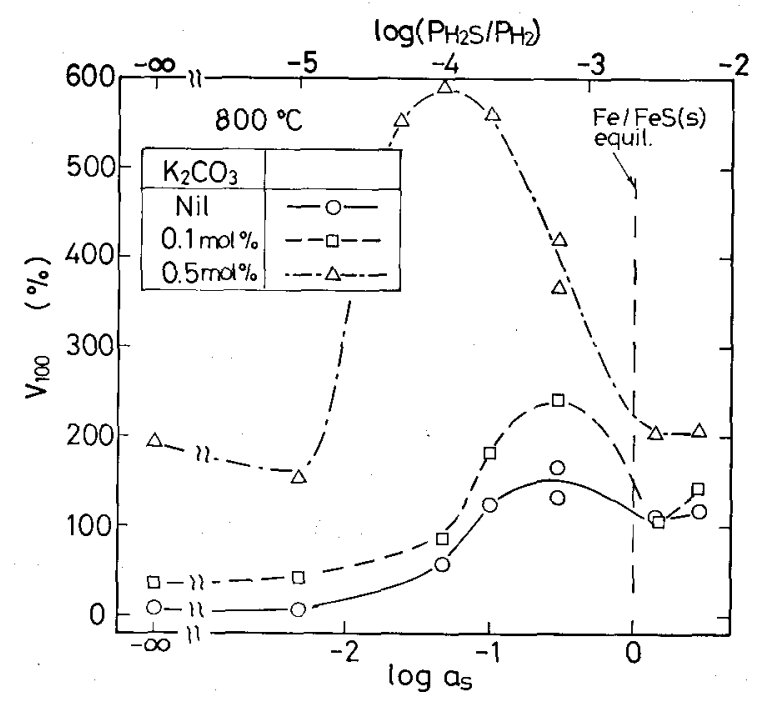

Fig. 3. Effect of sulphur potential on swelling during reduction of hematite pellets at $800^{\circ} \mathrm{C}\left(P_{\mathrm{H}_{2} \mathrm{O}} / P_{\mathrm{H}_{2}}=0.25\right)$.

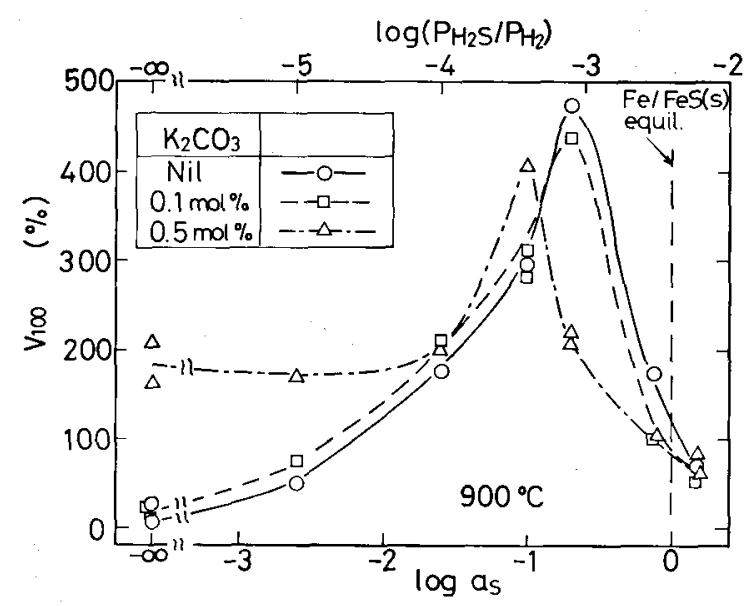

Fig. 4. Effect of sulphur potential on swelling during reduction of hematite pellets at $900^{\circ} \mathrm{C}\left(P_{\mathrm{H}_{2} \mathrm{O}} / P_{\mathrm{H}_{2}}=0.25\right)$.

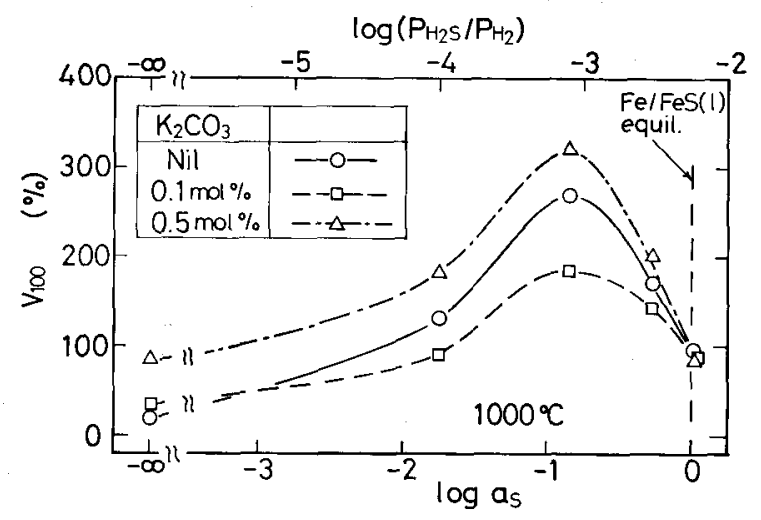

Fig. 5. Effect of sulphur potential on swelling during reduction of hematite pellets at $1000^{\circ} \mathrm{C}\left(P_{\mathrm{H}_{2} \mathrm{O}} / P_{\mathrm{H}_{2}}=\right.$ $0.25)$.

$0.5 \mathrm{~mol} \% \mathrm{~K}_{2} \mathrm{CO}_{3}$ lowered the value of $a_{\mathrm{S}}$ at maximum swelling of $800^{\circ} \mathrm{C}$. At $1000^{\circ} \mathrm{C}$, the $a_{\mathrm{S}}$ value at maximum swelling was insensitive to potassium.

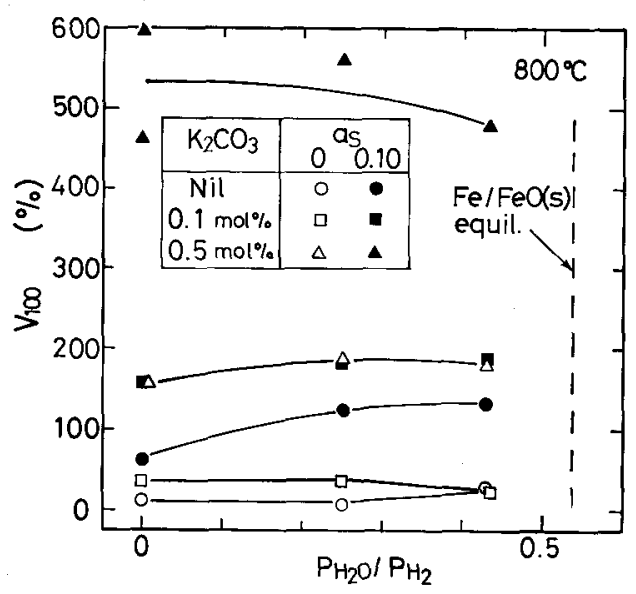

Fig. 6. Effect of oxygen potential on swelling during reduction of hematite pellets at $800^{\circ} \mathrm{C}$.

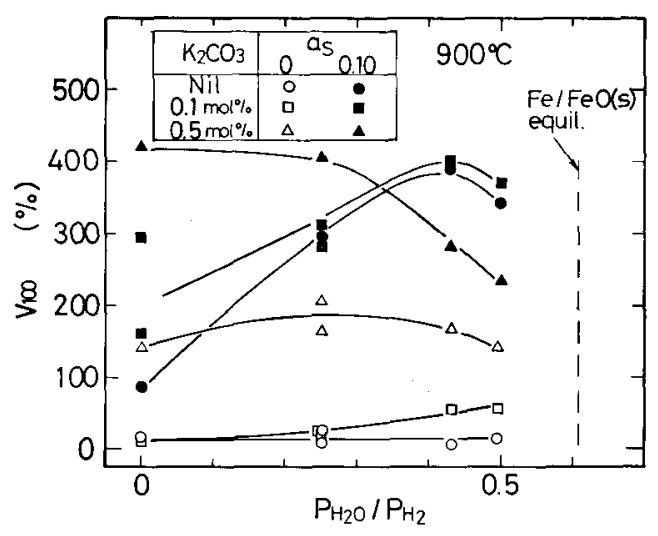

Fig. 7. Effect of oxygen potential on swelling during reduction of hematite pellets at $900^{\circ} \mathrm{C}$.

\subsubsection{Oxygen Potential Dependence of Swelling}

Oxygen potential dependence of swelling is shown in Figs. $6^{*}$ and $7^{*}$ for 800 and $900^{\circ} \mathrm{C}$, in the cases of hematite of $0,0.1$, and $0.5 \mathrm{~mol}_{0} / \mathrm{K}_{2} \mathrm{CO}_{3}$ at $a_{\mathrm{S}}=0$ and 0.10 . Swelling was insensible to oxygen potential at $800^{\circ} \mathrm{C}$. In cases of hematite of 0 and 0.1 mol $\% \mathrm{~K}_{2} \mathrm{CO}_{3}$ at $900^{\circ} \mathrm{C}$, the maximum swelling of $400 \%$ in $V_{100}$ was observed in vicinity of $P_{\mathrm{II}_{2} \mathrm{O}} / P_{\mathrm{HI}_{2}}=$ 0.40 and $a_{\mathrm{s}}=0.10$. For hematite containing 0.5 $\mathrm{mol} \% \mathrm{~K}_{2} \mathrm{CO}_{3}$ at $900^{\circ} \mathrm{C}$, the value of $V_{100}$ decreased gradually over $P_{\mathrm{H}_{2} \mathrm{O}} / P_{\mathrm{H}_{2}}=0.25$.

\subsubsection{Macro- and Microstructure}

External views of partially reduced pellets at $900^{\circ} \mathrm{G}$ are shown in Fig. 8. The coexistence of $0.5 \mathrm{~mol} \%$ $\mathrm{K}_{2} \mathrm{CO}_{3}$ and sulphur of $a_{\mathrm{S}}=0.10$ enhances the swelling markedly. Microstructures observed by SEM after partial reduction are shown in Figs. 9 and 10. When the degree of swelling is great, fine and long iron whiskers are found as seen in Figs. 9(b) and 10(b). For relatively small values of $V_{100}$, whiskers are coarse as shown in Figs. 9(c) and $10(\mathrm{a})$.

\subsection{Influence of Reduction History on Swelling}

In order to investigate the role of additives on swelling in detail, influence of holding at magnetite

\footnotetext{
* $P_{\mathrm{H}_{2} \mathrm{O}} / P_{\mathrm{H}_{2}}$ in equilibrium between iron and wustite is referred to our previous studies. ${ }^{21}$
} 
or wustite was examined. After reduction of hematite to a lower iron oxide with $\mathrm{CO}-\mathrm{CO}_{2}$ mixtures, the oxide was reduced stepwise to metallic iron with the hydrogen base gas. The results are listed in Table 2.

In case of $a_{\mathrm{S}}=0$, holding at magnetite increases values of $V_{100}$ slightly and holding at wustite decreases them rather than the case of no holding. In case of $a_{\mathrm{S}}=0.20$ at $900^{\circ} \mathrm{C}$ or 0.30 at $800^{\circ} \mathrm{C}$, values of $V_{100}$ are grcater as a whole than that of $a_{\mathrm{S}}=0$, and holding at magnetite and wustite decreases them except holding at magnetite of $0.5 \mathrm{~mol}_{0} \mathrm{~K}_{2} \mathrm{CO}_{3}$ doped hematite.

Macroviews after only holding at lower iron oxides are shown in Fig. 11. Except holding at wustite of $0.1 \mathrm{~mol} \% \mathrm{~K}_{2} \mathrm{CO}_{3}$ doped hematite, potassium grcatly enhances the formation of cracks. The values of $V$

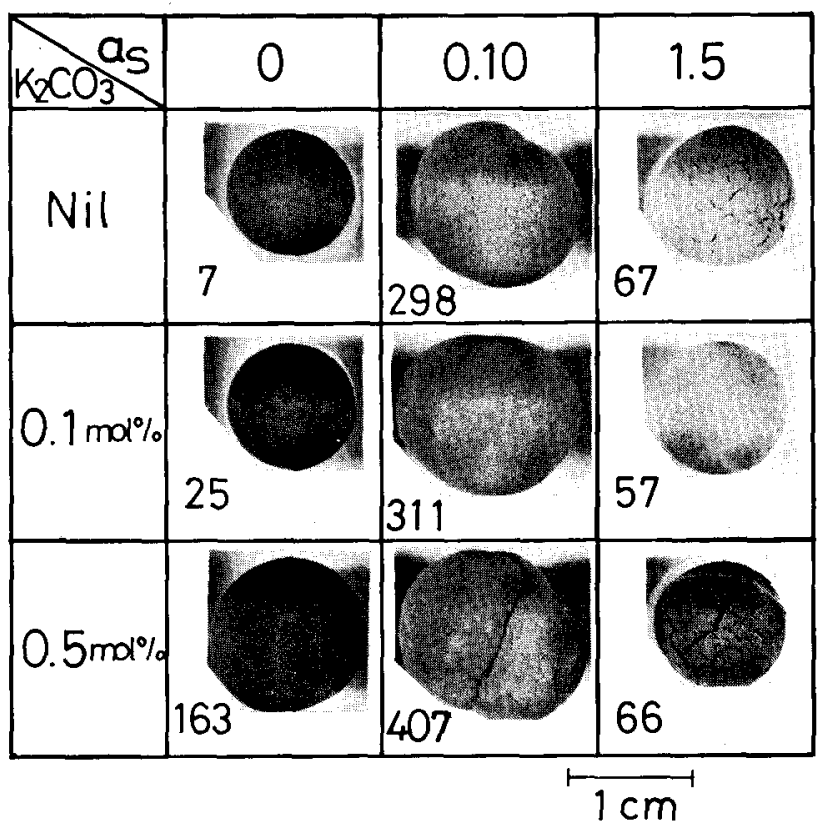

Fig. 8. External views of partially reduced pellets at $900^{\circ} \mathrm{C}$ $\left(P_{\mathrm{H}_{2} \mathrm{O}} / P_{\mathrm{H}_{2}}=0.25\right.$, numbers are the values of $V_{100}$ $(\%))$. (normal swelling) are small to be less than $40 \%$.

\subsection{Reduction Rate of Wustite}

The reduction rate of hematite to wustite was larger than that of wustite to iron as shown in previous study. ${ }^{3)}$ The apparent initial rates in the latter step of reduction $R_{W}$ * were plotted against the driving force of reduction, $\Delta C_{\mathrm{H}_{2}}=C_{\mathrm{H}_{2}}^{b}-C_{\mathrm{H}_{2}}^{e}\left(\mathrm{~mol} / \mathrm{cm}^{3}\right)$, as shown in Fig. 12, where $C_{\mathrm{H}_{2}}^{b}$ and $C_{\mathrm{H}_{2}}^{\mathrm{e}}$ are hydrogen concentrations in bulk gas and in equilibrium with iron and wustite, respectively.

Our previous study ${ }^{3}$ revealed that the rate controlling step during metallization should be the gas supply process under the condition of small amounts of hydrogen base gas such as $200 \mathrm{~cm}^{3} / \mathrm{min}$. Similar result was also obtained in the present work. That is, the mass transfer coefficient through gas film considering the balance resistance, $k_{F}(\mathrm{~cm} / \mathrm{s})$, can be calculated from Eqs. (3) and (4), and the total resistance, $Q_{t}^{M}(\mathrm{~s} / \mathrm{cm})$, can be measured from Eq. (5). Eq. (3) is known as Ranz and Marshall's equation. $r_{0}$ is initial radius of a pellet $(\mathrm{cm})$ and $U$ is gas flow rate $\left(\mathrm{cm}^{3} / \mathrm{s}\right)$. The ratios of both the values $\left(1 / k_{F}\right) / Q_{t}{ }^{M}$ are added in Fig. 12. As these values are roughly unity, the above mentioned process can be supported as the rate controlling step. Therefore, as is expected, $R_{W}$ is proportional to only $\Delta C_{\mathrm{II}_{2}}$ independently of the additives.

$$
\begin{aligned}
& S h=2.0+0.6 R e^{1 / 2} S c^{1 / 3} \\
& 1 / k_{F}=1 / k_{f}+4 \pi r_{0}^{2} / U \\
& R_{W} / 16=\Delta C_{\mathrm{II}_{2}} / Q_{t}^{M}
\end{aligned}
$$

\section{Discussion}

\subsection{Action of Potassium}

A part of potassium species added to hematite vapourize during the induration of pellets (Table 1). Some of potassium remained in the pellets after the induration is likely to form $\mathrm{KFe}_{11} \mathrm{O}_{17} \cdot{ }^{22)}$ Lattice pa-

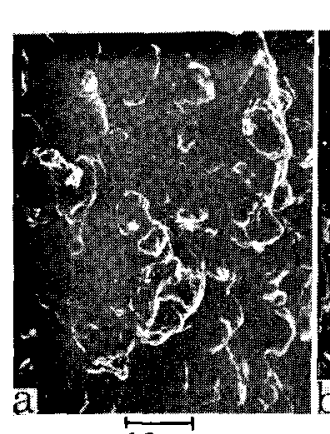

$\overrightarrow{10 \mu \mathrm{m}}$

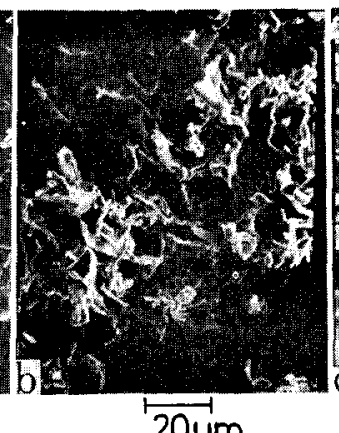

$20 \mu \mathrm{m}$

\begin{tabular}{llll}
\hline No. & a & b & c \\
\hline$a_{\mathrm{S}}$ & 0 & 0.20 & 1.5 \\
$V_{100}$ & 7 & 474 & 67
\end{tabular}

Fig. 9. Iron morphology observed by SEM after partial reduction of pure hematite pellets with $80 \% \mathrm{H}_{2}-20 \% \mathrm{H}_{2} \mathrm{O}$ mixtures at $900^{\circ} \mathrm{G}$.

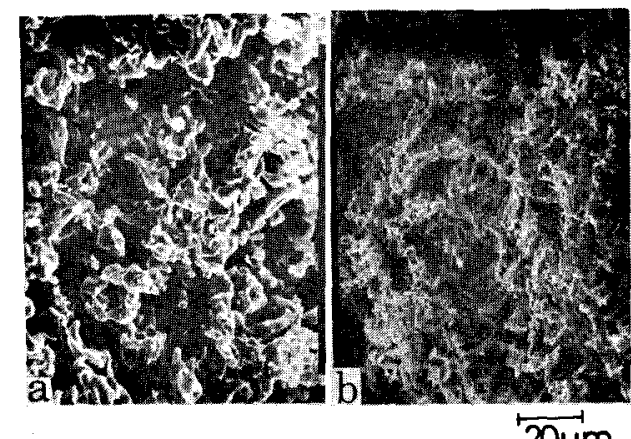

\begin{tabular}{cccc} 
& & & \multirow{20\mu\mathrm{m}}{}{} \\
\hline No. & $\begin{array}{c}\text { Temperature } \\
\left({ }^{\circ} \mathrm{C}\right)\end{array}$ & $a_{\mathrm{S}}$ & $V_{100}$ \\
\hline $\mathrm{a}$ & 900 & 0 & 208 \\
$\mathrm{~b}$ & 800 & 0.048 & 593 \\
\hline
\end{tabular}

Fig. 10. Iron morphology observed by SEM after partial reduction of $0.5 \mathrm{~mol} \% \mathrm{~K}_{2} \mathrm{CO}_{3}$ doped hematite pellets with $80 \% \mathrm{H}_{2}-20 \% \mathrm{H}_{2} \mathrm{O}$ mixtures.

* Oxygen removal per external area and time $\left(\mathrm{g} / \mathrm{cm}^{2} \mathrm{~s}\right)$. 
Table 2. Effect of holding at magnetite and wustite on swelling during reduction of hematite to iron.

\begin{tabular}{|c|c|c|c|c|c|c|c|c|c|c|c|}
\hline \multirow{3}{*}{$\begin{array}{c}\text { Pellet } \\
\left(\mathrm{mol}^{\prime} \%\right. \\
\left.\mathrm{K}_{2} \mathrm{CO}_{3}\right)\end{array}$} & \multirow{3}{*}{$\begin{array}{l}\text { Reaction } \\
\text { tempera- } \\
\text { ture } \\
\left({ }^{\circ} \mathrm{C}\right)\end{array}$} & \multicolumn{6}{|c|}{$V_{100}$ value $(\%)$} & \multicolumn{4}{|c|}{ Only hold } \\
\hline & & \multicolumn{3}{|c|}{$a_{\mathrm{S}}=0$} & \multicolumn{3}{|c|}{$a_{\mathrm{S}}=0.20^{*}$ or $0.30^{* *}$} & \multicolumn{2}{|c|}{$M$} & \multicolumn{2}{|r|}{$W$} \\
\hline & & No hold & $M$ & $W$ & No hold & $M$ & $w$ & $\mathrm{a}$ & $\mathrm{b}$ & a & $\mathrm{b}$ \\
\hline \multirow{2}{*}{ Pure } & 900 & 27 & 34 & 22 & 472 & 203 & 163 & 29 & - & 12 & - \\
\hline & 800 & 6 & 25 & 27 & 150 & 54 & 87 & 16 & - & 15 & - \\
\hline \multirow{2}{*}{0.1} & 900 & 15 & 62 & 7 & 438 & 243 & 125 & 20 & $18.8(0.028)$ & 10 & $7.5(0.029)$ \\
\hline & 800 & 37 & 80 & 63 & 244 & 230 & 131 & 23 & $9.8(0.029)$ & 12 & $2.8(0.026)$ \\
\hline \multirow{2}{*}{0.2} & 900 & 62 & 56 & 4 & - & - & - & 21 & $17.9(0.079)$ & 14 & $9.1(0.071)$ \\
\hline & 800 & 23 & 64 & 45 & - & - & - & 33 & $14.6(0.081)$ & 26 & $5.1(0.075)$ \\
\hline \multirow{2}{*}{0.5} & 900 & 185 & 155 & 94 & 214 & 238 & 172 & 37 & - & 41 & - \\
\hline & 800 & 193 & 245 & 117 & 393 & 508 & 200 & 33 & - & 27 & - \\
\hline
\end{tabular}

$* 900^{\circ} \mathrm{C}, \quad * * 800^{\circ} \mathrm{C}$

$M$ : Magnetite ( $2 \mathrm{~h}$ holding in 10\% CO-90\% $\mathrm{CO}_{2}$ mixture), $W:$ Wustite (30 min holding in $50 \% \mathrm{CO}-50 \% \mathrm{CO}_{2}$ mixture)

$a: V$ value $(\%), b$ : Surface coverage of potassium atom obtained from standardizing intensities of Auger peaks $\mathrm{K}(254 \mathrm{eV}), \mathrm{O}$ $(52 \mathrm{l} \mathrm{eV})$, and $\mathrm{Fe}(715 \mathrm{eV})$ at room temperature (at \%), Parentheses : total $\mathrm{wt} \% \mathrm{~K}_{2} \mathrm{CO}_{3}$.

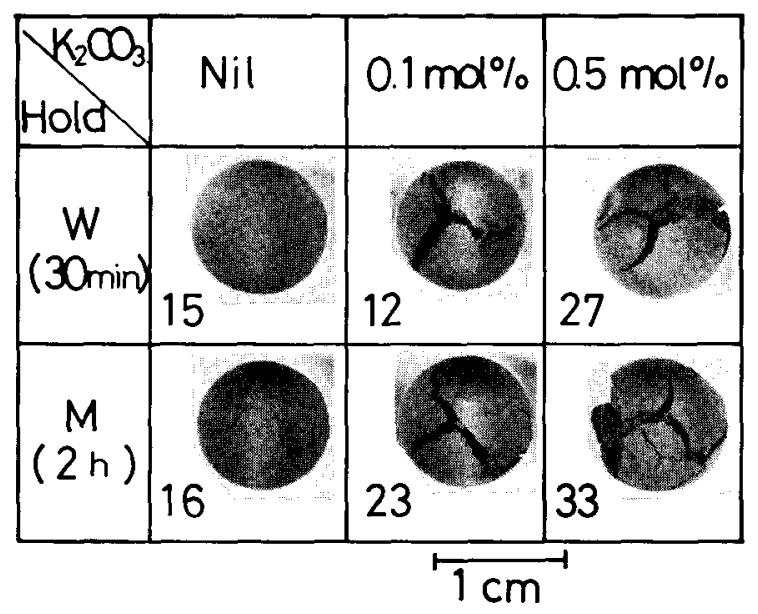

W: Wustite

$M$ : Magnetite

Numbers are the values of $\mathbf{V}$.

Fig. 11. External views after complete reduction of hematite pcllets to lower iron oxides in $\mathrm{CO}-\mathrm{CO}_{2}$ mixtures at $800^{\circ} \mathrm{G}$.

rameter measurement of iron oxides containing potassium by X-ray diffraction and EPMA analysis of potassium present in them were carried out in the present work. It was found from the results that no more than $0.1 \mathrm{wt} \% \mathrm{~K}$ dissolve in bulks of three kinds of iron oxides. The low solubility of potassium in wustite was also detected by Gougeon el al. ${ }^{23)}$ Therefore, a large part of potassium is expected to exist on the surface of iron oxides. That can be also supported through high surface coverage of $\mathrm{K}$ as added in Table 2.

Abnormal swelling with iron whiskers due to only potassium as shown in Fig. 2 and 'Table 2 is expected to be caused largely by the adsorption of potassium species on reduced iron surface rather than by some ideas ${ }^{7,9,12,16)}$ based on their distribution state within iron oxides before or during metallization. It is derived from following facts that any swelling with only $\mathrm{CaO}$, which does not have volatility, does not occur except normal swelling regardless of reduction his-

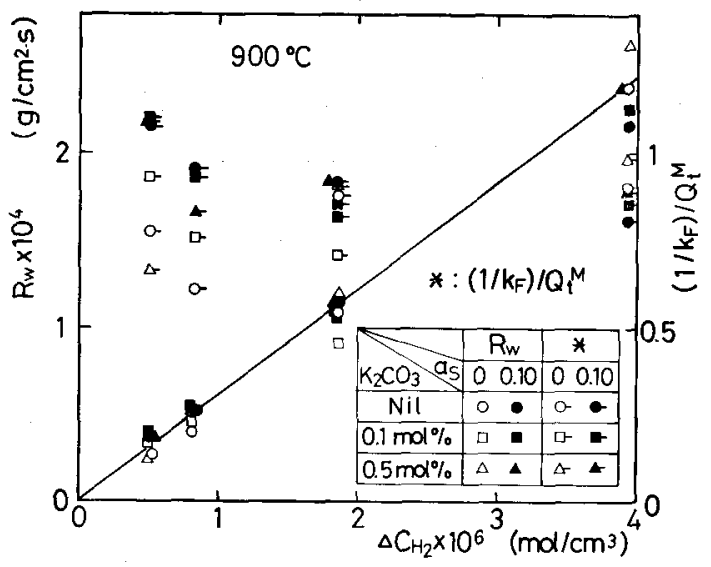

Fig. 12. Effects of $\Delta C_{\mathrm{H}_{2}}$ and addition of potassium and sulphur on values of $R_{W}$ and $\left(1 / k_{H^{\prime}}\right) / Q_{t}^{M}$ at $900^{\circ} \mathrm{C}$.

tories to wustite stage $\mathrm{e}^{1,3)}$ and the adsorption on iron is analogous to one of two prominent actions of sulphur in promoting whiskers described in Sec. 4.2 (later Table 3).

Apparent partial pressure of potassium in gas phase during metallization, $P_{\mathrm{K}}$, was roughly estimated from the loss of $\mathrm{K}$ and the gas flow rate during heating of wustite. The relationship between $P_{\mathrm{K}}$ and $V_{100}$ is exhibited in Fig. 13. The swelling reaches a saturated state above $P_{\mathrm{K}}=10^{-5}$ atm. Potassium probably exists as $(\mathrm{K}+\mathrm{O})$ adlayer on metallic iron. ${ }^{24)}$ It is considered in the reduction of iron oxides without potassium that a large part of metallic iron precipitates at the active metal/oxide/gas triple junction ${ }^{25)}$ and the product morphology is developed to the lateral growth on wustite owing to the lowest energy of $\mathrm{Fe} / \mathrm{FeO}$ interface compared with the high surface energies of both the solids. ${ }^{11}$ On the other hand, the reduction in presence of potassium probably facilitates the iron precipitation at $\mathrm{Fe} / \mathrm{FeO}$ interface to enhance the upwards growth such as whiskers. That may be attributed to inactivation of the triple junction due to the formation of $(\mathrm{K}+\mathrm{O})$ adlayer on reduced iron.

Moreover, it is expected that potassium on wustite 
Table 3. Comparison of effects of potassium and sulphur for reduction and swelling behaviour during metallization.

\begin{tabular}{|c|c|c|c|c|c|c|c|c|c|}
\hline \multirow[b]{2}{*}{ Element } & \multirow{2}{*}{$\begin{array}{l}\text { Temp. at } \\
\text { max. } \\
\text { swelling } \\
\left({ }^{\circ} \mathrm{C}\right)\end{array}$} & \multirow{2}{*}{$\begin{array}{c}\operatorname{Max} . \\
V_{100} \\
(\%)\end{array}$} & \multirow{2}{*}{$\begin{array}{c}\text { Iron } \\
\text { whisker }\end{array}$} & \multicolumn{2}{|c|}{ Metallic iron } & \multicolumn{4}{|c|}{ Wustite } \\
\hline & & & & $\begin{array}{l}\text { Adsorption } \\
\text { structure }\end{array}$ & $\begin{array}{l}\text { Surface } \\
\text { energy }\end{array}$ & $\begin{array}{l}\text { Chemical } \\
\text { reaction }\end{array}$ & $\begin{array}{l}\text { Surface } \\
\text { segregation }\end{array}$ & $\Delta C_{\square}$ & $\begin{array}{l}\text { Inter- } \\
\text { diffusion }\end{array}$ \\
\hline Potassium & 800 & 300 & Coarce & $\begin{array}{l}(\mathrm{K}+\mathrm{O}) \\
\text { adlayer }{ }^{24)}\end{array}$ & $\begin{array}{l}\text { A little } \\
\text { decrease }\end{array}$ & $\begin{array}{l}\text { Accele- } \\
\text { ration }\end{array}$ & $\begin{array}{l}\text { Large } \\
\text { (Table 2) }\end{array}$ & Decrease & $\begin{array}{l}\text { Increase } \\
\text { of surface } \\
\text { diffusion }\end{array}$ \\
\hline Sulphur & 900 & 500 & Fine & $\mathrm{C}(2 \times 2) \mathrm{S}$ & $\begin{array}{l}\text { Large } \\
\text { decrease }\end{array}$ & $\begin{array}{l}\text { Decele- } \\
\text { ration }\end{array}$ & Small ${ }^{27)}$ & Increase & $\begin{array}{l}\text { Invariable } \\
\text { (?) }\end{array}$ \\
\hline
\end{tabular}

$\Delta C_{[]]}$: Super saturation degree of cation vacancy in wustite for iron nucleation ${ }^{1)}$

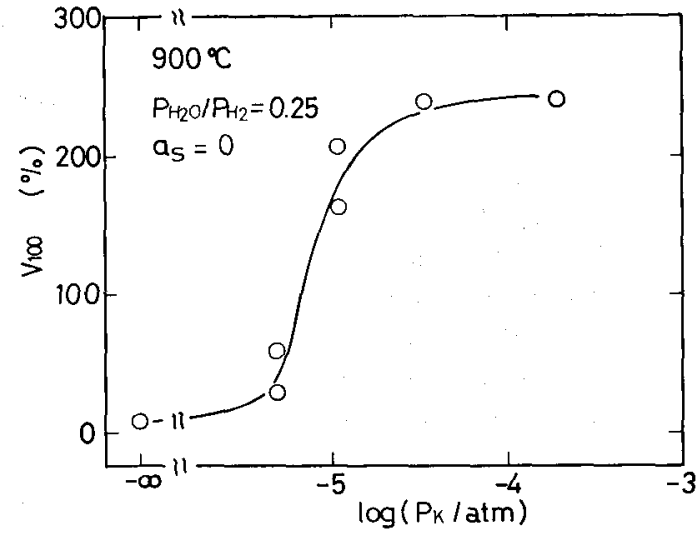

Fig. 13. Relationship between $V_{100}$ and potassium pressure at $900^{\circ} \mathrm{C}$.

surface forms the complex with iron oxides and it can be reduced easily into metallic iron. It means lowering the degree of super saturation of iron vacancy in wustite required for iron nucleation, ${ }^{11} J C_{\square}$, presented by Ilschner, ${ }^{26)}$ as well as the case of CaO. ${ }^{3)}$ This will give an unfavourable condition for formation of iron whiskers. They are different from the case of sulphur ${ }^{1)}$ having the high value of $\Delta C_{\square}$.

However, potassium is also expected to increase the diffusion flux of iron cation on wustite surface, otherwise it can not be explained that the values of $V_{100}$ obtained in three processes with potassium and without sulphur as given in Table 2 are larger for reduction steps of no hold and $M$ than for reduction step of $W$. Since surface coverage of potassium atoms on magnetite is higher than that on wustite as indicated in Table 2, interdiffusion between potassium and iron on wustite surface during metallization probably occurs more favourably for the former oxide. This is also supported by the fact that $V_{100}$ of $0.5 \mathrm{~mol}^{\%}$ $\mathrm{K}_{2} \mathrm{CO}_{3}$ doped hematites in condition of lower $P_{\mathrm{H}_{2} \mathrm{O}} /$ $P_{\mathrm{I}_{2}}$ (Fig. 7) are kept at upper level similarly to the case of $\mathrm{CaO}^{31}$

\subsection{Comparison of Potassium and Sulphur}

As the reduction stage of wustite to iron is of importance to elucidate swelling mechanism with whiskers, actions of potassium and sulphur against both solids of metallic iron and wustite are listed up each other in Table 3.

Two actions of sulphur described in previous works ${ }^{1,3)}$ are as follows: decreasing the opportunity for iron nucleation by increasing $\Delta C_{\square}$ and making the

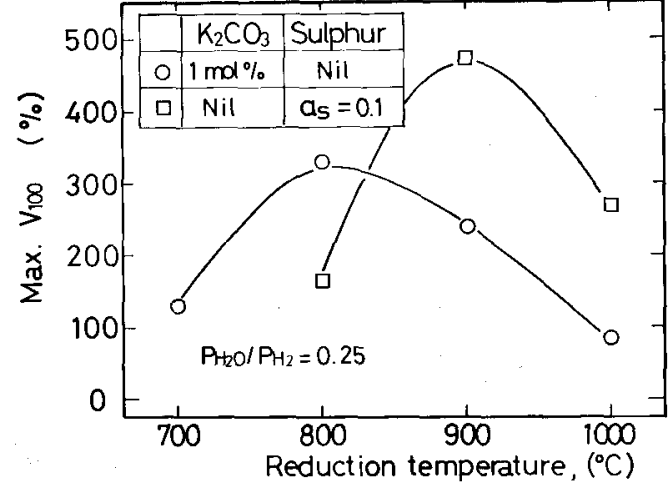

Fig. 14. Influences of additives and reduction temperature on maximum $V_{100}$.

metal/oxide/gas triple junction inactive through sulphur adsorption on both the solid phases. Concerning the latter action, it is considered that sulphur adsorbs on iron surface more intimately and lowers its surface energy more intensely than potassium forming $(\mathrm{K}+\mathrm{O})$ adlayer, because the former makes iron whiskers longer and finer than the latter.

It was measured by AES, on the other hand, that potassium segregated on wustite surface in more amounts than sulphur. ${ }^{27)}$ Though no knowledge concerning effects of additives on surface energy of wustite was obtained in present work, two points related to wustite phase would be mentioned below: sulphur increases $\Delta C_{\square}$ and potassium enhances interdiffusion on the surface.

Nicolle et al. ${ }^{\text {*) }}$ explained the whisker formation with sulphur from the change of rate controlling processes based on sulphur adsorption on wustite. But, their idea could not be applied for the formation of whiskers relating potassium, because potassium accelerates the chemical reaction and it is unfavourable for the formation. Accordingly, a mechanism on the basis of surface energy of metallic iron would be perhaps the most important for the growth process.

The relation between maximum $V_{100}$ and reduction temperature is shown in Fig. 14 for each additive. The peak exists at $800^{\circ} \mathrm{C}$ for potassium and at $900^{\circ} \mathrm{C}$ for sulphur. These temperatures for maximum swelling coincided with results in Table 2 , where $V_{100}$ obtained in presence of sulphur for holding pure hematite at magnetite or wustite become larger values at $900^{\circ} \mathrm{C}$ than at $800^{\circ} \mathrm{C}$, and those obtained in holding experiments using $0.5 \mathrm{~mol} \% \mathrm{~K}_{2} \mathrm{CO}_{3}$ doped hematite indicate reverse temperature dependence. 


\subsection{Behaviour in Coexistence of Potassium and Sulphur}

It is expected from our previous work ${ }^{1)}$ that when liquid phase in $\mathrm{Fe}-\mathrm{K}-\mathrm{O}-\mathrm{S}$ system (not detectable by EPMA in this work) is not formed at Fe/FeO interface, cooperative actions by both the additives (sulphur adsorption on iron and enhancement of diffusion on wustite) become effective to lead to the largest swelling $\left(V_{100}=600 \%\right)$ at $800^{\circ} \mathrm{C}$. When the reduction proceeds under the conditions beyond the sulphur potential at maximum swelling, it indicates gradual decrease of swelling with increasing the potential. That may be attributed to suppression of the reaction between gas and wustite and of the fast surface diffusion required for the formation of whiskers. These suppression probably comes from the formation of liquid phase covered over wustite. Regarding the oxygen potential dependence of swelling as shown in Fig. 7, it will be explained in combination of such a mechanism as developed by Nicolle et al. ${ }^{61}$ and the tendency for the liquid to be formed with its potential.

In case of hematite containing $0.5 \mathrm{~mol} \% \mathrm{~K}_{2} \mathrm{CO}_{3}$ at $900^{\circ} \mathrm{C}$, activity of each component in liquid phase assumed to be formed at maximum swelling was estimated by using $P_{\mathrm{K}}$ in Fig. 13, standard Gibbs energies of following reactions, ${ }^{28)} \Delta G^{\circ}$, and $P_{\mathrm{O}_{2}}\left(P_{\mathrm{H}_{2} \mathrm{O}} /\right.$ $\left.P_{\mathrm{H}_{2}}=0.25\right)$ and $P_{\mathrm{S}_{2}}\left(a_{\mathrm{S}}=0.10\right)$ in Fig. 4.

$$
\begin{gathered}
2 \mathrm{~K}(g)+1 / 2 \mathrm{O}_{2}(g)=\mathrm{K}_{2} \mathrm{O}(l) \\
\Delta G^{\circ} / \mathrm{cal}=-114100+60.3 T \\
2 \mathrm{~K}(g)+1 / 2 \mathrm{~S}_{2}(g)=\mathrm{K}_{2} \mathrm{~S}(l) \\
\Delta G^{\circ} / \mathrm{cal}=-143800+61.7 T
\end{gathered}
$$

They are evaluated as follows; $a_{\mathrm{K}_{2} \mathrm{O}}=1.5 \times 10^{-11}$, $a_{\mathrm{K}_{2} \mathrm{~S}}=0.021, a_{\mathrm{VeO}}=0.16$, and $a_{\mathrm{FeS}}=0.10$.

The ternary eutectic temperature in $\mathrm{Fe}-\mathrm{O}-\mathrm{S}$ system is known as $920^{\circ} \mathrm{C}$. ${ }^{29}$ ) Because $\mathrm{K}_{2} \mathrm{~S}$ has a low melting point of $840^{\circ} \mathrm{C}$, addition of potassium into this system likely facilitates the formation of liquid phase in lower sulphur potential at $900^{\circ} \mathrm{C}$.

Present work confirmed that abnormal swelling due to only potassium occurred surely to a moderate extent even without sulphur. As the coexistence of both the additives also made the abnormal swelling more markedly, this cooperative effect is desirable to be interpreted deeply in future. Moreover, reduction experiments under the coexistence of sodium and sulphur should be carried out.

\section{Conclusion}

In order to make clear the cooperative effects of potassium and sulphur on catastrophic swelling during reduction of iron oxides, hematite pellets containing potassium carbonate were reduced with hydrogen base gas bearing sulphur at the temperature of 800 to $1000^{\circ} \mathrm{C}$ under the rate controlling of gas supplying.

The addition of $0.1 \sim 2.0 \mathrm{~mol}_{0} \mathrm{~K}_{2} \mathrm{CO}_{3}$ caused normal swelling in which the degree was below $40 \%$ accompanying macro- and microscopic cracks and abnormal swelling which reached a maximum of $300 \%$ at $800^{\circ} \mathrm{C}$ with coarse iron whiskers. This ab- normal swelling due to only potassium occurred regardless of reduction processes and that was likely attributed to a mechanism based on the adsorption of potassium on iron surface and increase of diffusion flux of iron on wustite surface.

Abnormal swelling of pure hematite occurred in the sulphur activity of $10^{-2} \sim 1$ and the maximum swelling was found at around 0.1 of the activity similarly to authors' previous study. The maximum swelling due to sulphur reached $500 \%$ at $900^{\circ} \mathrm{C}$ with fine iron whiskers. Sulphur had obviously stronger effects than potassium for the swelling, probably owing to the prominent ability of lowering surface energy of iron.

The largest swelling of $600 \%$ was observed at $800^{\circ} \mathrm{C}$ in coexistence of potassium and sulphur without the formation of liquid phase. The addition of potassium lowered the sulphur potential at which maximum swelling occurred.

If the gasification behaviour of sulphur during induration and reduction for commercial and synthesized ores can be understood as next steps, the relationship between the present work and previous ones regarding the swelling behaviour will be made more clearly.

\section{REFERENCES}

1) S. Hayashi, Y. Iguchi and J. Hirao: Tetsu-to-Hagané, 71 (1985), 1311.

2) S. Hayashi, Y. Iguchi and J. Hirao: Trans. Iron Steel Inst. $J p n ., 26$ (1986), 528.

3) S. Hayashi, Y. Iguchi and J. Hirao: Tetsu-to-Hagané, 73 (1987), 1668.

4) R. Nicolle, M. Schneider and F. Temoin: Ironmaking Steelmaking, 39 (1980), 153.

5) H. de Haas, K. Grebe and F. Oeters: Arch. Eisenhüttenwes., 51 (1980), 167.

6) R. Nicolle and A. List: Metall. Trans. B, 10B (1979), 429.

7) R. L. Bleifuss: Trans. AME/AIME, 247 (1970), 225.

8) H. vom Ende, K. Grebe and S. Thomalla: Stahl Eisen, 91 (1971), 815.

9) W-K. Lu: Scand.J. Melall., 3 (1974), 49.

10) T. El Kasabgy and W-K. Lu: Metall. Trans. B, 11B (1980), 409.

11) G. E. Seaton, J. S. Foster and J. Velasco: Trans. Iron Steel Inst. Jpn., 23 (1983), 497.

12) H. vom Ende, K. Grebe and S. Thomalla: Stahl Eisen, 90 (1970), 667.

13) T. Nakazawa, M. Sasaki, K. Ito and S. Kondo: Tetsu-toHagané, 58 (1972), 1039.

14) W-K. Lu: Scand.J. Metall., 2 (1973), 65.

15) Y. Ueda, S. Sayama, Y. Nishikawa, Y. Suzuki and S. Nobuoka: Telsu-to-Hagané, 68 (1984), 2046.

16) K. Narita and M. Maekawa: Tetsu-to-Hagané, 59 (1973), 318.

17) Y. Shimomura, K. Nishikawa, S. Arino, T. Katayama, Y. Hida and T. Isoyama: Tetsu-to-Hagané, 62 (1976), 547.

18) H. Rausch, A. Saatci, W. Thumm and F. Oeters: Arch. Eisenhüttenwes., 46 (1975), 623.

19) E. T. Turkdogan, S. Ignatowicz and J. Pearson: J. Iron Steel Inst., 177 (1955), 349.

20) K. Ono, A. Yamaguchi and J. Moriyama: J. Jpn. Inst. Met., 35 (1971), 871.

21) S. Hayashi and Y. Iguchi: Tetsu-to-Hagané, 74 (1988), 656.

22) J. Roederer, B. Dupre and C. Gleitzer: Steel Res., 58 
ISIJ International, Vol. 29 (1989), No. 8

(1987), 247.

23) M. Gougeon, B. Dupre and C. Gleitzer: Metall. Trans. B, 17B (1986), 657.

24) G. Ert1, D. Prigge, R. Schloegl and M. Weiss: J. Catalysis, 79 (1983), 359.

25) M. Chang and L. C. De Jonghe: Metall. Trans. B, 15B (1984), 685.
26) B. Ilschner: Z. Metallkd., 55 (1964), 153.

27) S. Hayashi and Y. Iguchi: ISIJ Int., 29 (1989), 596.

28) M. Tokuda and M. Otani: Bull. Res. Inst. Min. Dress. Met., Tohoku Univ., 32 (1976), 119.

29) D. C. Hilty and W. Crafts: Trans. AIME, 194 (1952), 1307. 